\title{
INFLUENCE OF ENVIRONMENTAL FACTORS ON REPRODUCTION OF POLAR VASCULAR PLANTS
}

\author{
WIOLETA KELLMANN-SOPYŁA ${ }^{1}$, MARTA PASTORCZYK ${ }^{1}$, \\ IRENA GIEŁWANOWSKA ${ }^{1,2}$ \\ ${ }^{1}$ Department of Plant Physiology and Biotechnology, University of Warmia and \\ Mazury, Oczapowskiego 1A, 10-719 Olsztyn, Poland \\ ${ }^{2}$ Department of Antarctic Biology, Polish Academy of Sciences, \\ Ustrzycka 10, 02-141 Warszawa, Poland \\ e-mail: wioleta.kellmann@uwm.edu.pl \\ e-mail: marta.pastorczyk@uwm.edu.pl \\ e-mail: i.gielwanowska@uwm.edu.pl
}

\begin{abstract}
In the last few decades, changes of reproductive pattern of polar vascular plants have been observed, for the benefit of generative propagation. The reasons for this phenomenon are attributed to intensively following climate change, whose effects may be various. Warming causes the production of the greater number of generative structures, with higher quality. Our macroscopic observations conducted on specimens of polar vascular plants, cultivated in University of Warmia and Mazury greenhouse, indicate that the effect of temperature increase on flower development and seed formation is inconsistent. On the other hand enhanced levels of UV-B radiation can negatively affect seedlings. The complexity of the climate change causes tremendous difficulties in defining a clear and unquestioned way of modifications during the reproductive phase of the described plants.
\end{abstract}

KEY WORDS: climate change; generative reproduction; polar vascular plants.

\section{INTRODUCTION}

The polar vascular plants are capable to produce both vegetative and generative propagules (as seeds). However, their participation in reproduction is not equal and constant in time. The environmental conditions, in which the population exists, have a big impact on the reproductive pattern. Therefore, the way of species 
spreading in time and space is considered as a one of adaptation strategies to different environments. Among the polar flowering plants, a larger participation of asexual reproduction is observed. Thus, it seems reasonable to assume that this is more profitable in harsh climatic conditions, due to less dependence on the length of growing season and its conditions, as opposed to sexual reproduction. The vegetative propagation is characterized by very high efficiency, reaching $90-100 \%$ (Callaghan and Emanuelsson 1985). The survival of offspring is high, because the transformation of seedlings into the juvenile stage is omitted (Pirożnikow 1996). Due to the high plasticity and morphological diversity of vegetative progeny, plants can better manage energy resources (Callaghan and Emanuelsson 1985). In contrast to the vegetative reproduction, the generative propagation is sensitive to environmental disturbances, which are very typical and frequent in the polar regions. The disturbances are associated with the lower production of mature and viable seeds. According to Edwards and other authors, although, the only two native vascular plants occurring in the Antarctic produce plenty of flowers (inflorescences), the seeds produced at a later stages are often dead (Edwards 1974, Convey 1996). Reduction in the formation of viable seeds was also observed in the Arctic, in Dryas octopetala, this coincided with the occurrence of low temperatures during the growing season (Wookey et al. 1993). On the other hand, in the last few years, there have been numerous reports concerning the changes in a reproductive pattern, for the benefit of the generative reproduction among vascular plants of the polar regions. This fact is linked to climate change observed for several decades in these areas, which are characterized by far greater rate of changes than in other latitudes. Observations and experiments conducted in the polar areas in the context of these changes have resulted in many interesting insights.

\section{CHANGES CAUSED BY AIR TEMPERATURE INCREASE}

The Antarctic Peninsula is the fastest warming region of Earth. Over the past 50 years, on its west coast mean annual air temperature has risen approximately $2.6^{\circ} \mathrm{C}$ (King 1994; Smith et al. 1996). Therefore, it is a convenient area for determining the effects of temperature rise on the plant populations. On the basis of field experiment carried out on this peninsula, Day et al. (1999) recorded increase in the number of produced generative structures reaching maturity stadium and increase in the intensity of their development in both Deschampsia antarctica and Colobanthus

Figure 1. Antarctic flowering plants growing under various environmental conditions $\mathrm{a}, \mathrm{d}$ - the plants growing under natural conditions (the Antarctic - King Georg Island, in the Admiralty Bay region). On the specimen of: Colobanthus quitensis (a) numerous of mature seed-bags and young flower buds and $D$. antarctica $(\mathrm{d})$ young inflorescences are visible; b,c,e, $\mathrm{f}$ - the plants growing in a greenhouse of University of Warmia and Mazury, at temperature of about $20^{\circ} \mathrm{C}$. On the specimens of C. quitensis (b) and D. antarctica (e) cultivated during one month, the abundant flowers are visible. The elderly specimens of $C$. quitensis (c) and D. antarctica (f) without generative structures cultivated during two years. 

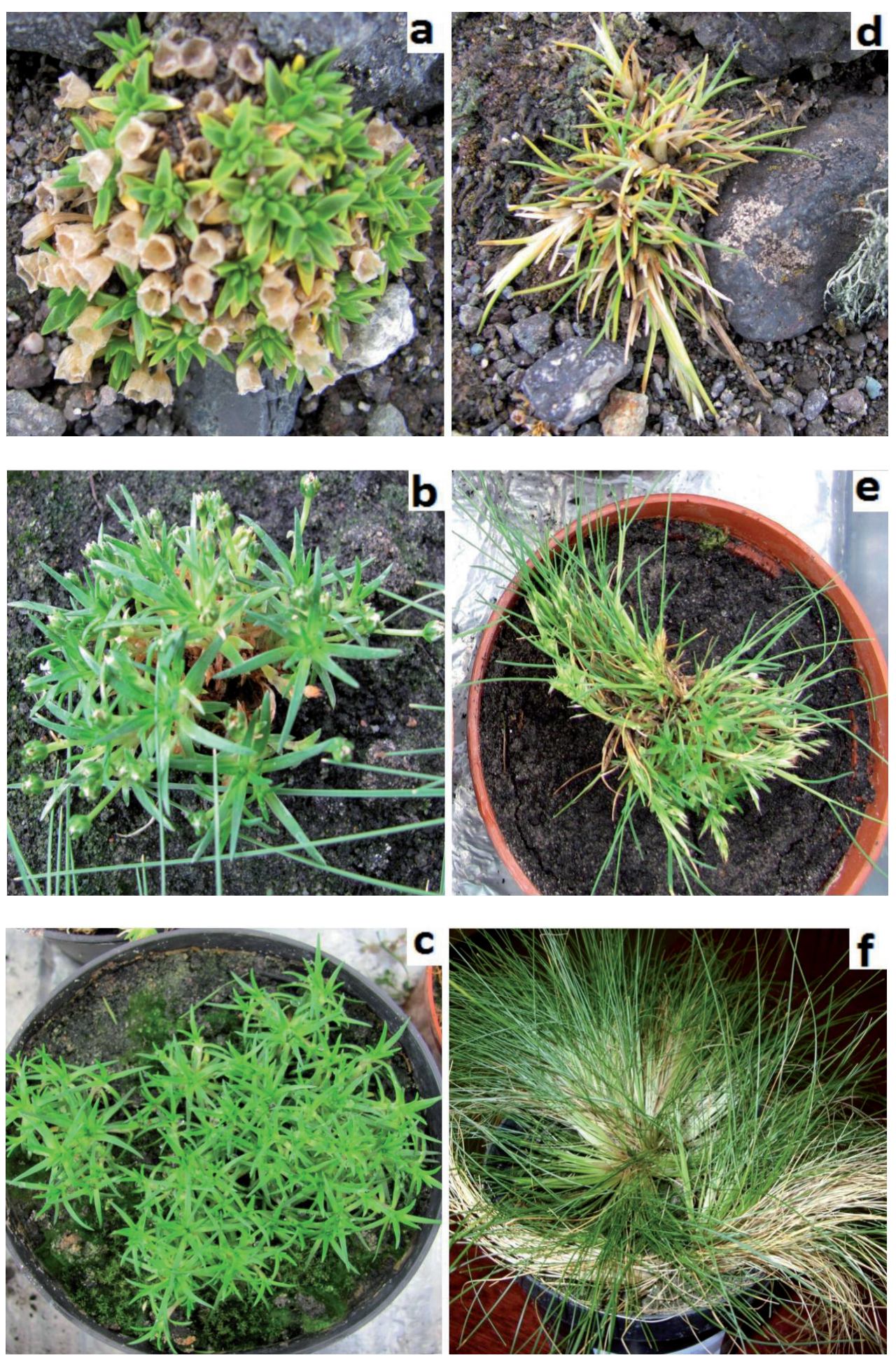
quitensis under influence of air warming (Fig. 1a, d). A similar positive effect was demonstrated in relation to the propagation of $D$. octopetala, the species occurring in the zone of polar semi-desert, in Svalbard (Wookey et al. 1995). Additionally, it was founded that capsules of $C$. quitensis produced higher number of seeds with greater mass. It is believed that such direction of change might be responsible for the improvement of both germinability of diaspores and seedling survivorship. During monitoring carried out by more than 30 years on the Argentine Islands and on the Signy Island, the series of growing seasons with increased temperatures were recorded, after which the recruitment of seedlings of these species has increased (Smith 1994).

An optimum air temperature for efficient germination both $D$. antarctica and $C$. quitensis is ca. $20^{\circ} \mathrm{C}$ (Edwards 1974). The culture of polar vascular plants, which has been conducted in University of Warmia and Mazury greenhouse (established in 2002), at temperature closed to the above, consists of numerous Arctic and Antarctic specimens. In theyear 2010, thenew individuals of vascularplants collected during the $34^{\text {th }}$ Polish Antarctic Expedition were added. These specimens after transplanting into pots and placed in the greenhouse take the further growth and development quickly. The stable conditions caused formation of numerous and lush vegetative shoots and provided abundant flowering, which was ended with seed production (Fig. 1b, e). However, it should be noted that inflorescences of these plants are initiated at the end of the growing season preceding the development of flowers and seed set (Edwards 1974). This confirms the assumption that the initiation of generative reproduction was taken place under natural conditions, whereas thermal equilibrium allowed only on undisturbed development process of sexual reproduction elements. On the other hand the elderly specimens - imported from the previous polar expeditions - regenerated by means of seeds or vegetative shoots produce not too many flowers under greenhouse conditions (Fig. 1c, f). This is the most evident in the case of D. antarctica, in which they occur very rarely (hardly ever) (Fig. 1f).

Our preliminary comparative evaluation of $C$. quitensis seeds, which were produced both under natural and greenhouse conditions showed some differences at the morphological and physiological level. These are related to their weight and size, as well as the germinability. The results suggest that the diaspores from the natural conditions are heavier and more viable (unpublished data). However, for the final confirmation of these observation are required further studies.

\section{CHANGES CAUSED BY ENHANCED LEVELS OF UV-B RADIATION}

The increase in the intensity of UV-B radiation reaching the earth's surface is also classified to climatic changes, which are observed in the polar regions. The largest increase of this factor, like the temperature increase mentioned above, 
is recorded on the Antarctic Peninsula. In the past five decades there has been reported twofold increase in the intensity of ultraviolet radiation (Day et al. 1999). The warming trend and its consequences suggest its positive effect, whereas the influence of UV-B radiation on plants is rather negative. Results of studies carried out on seedlings of C. quitensis by Ruhland and Day (2001), did not indicate the impact of enhanced levels of UV-B radiation on the seedling survivorship, but reported a reduced number of leaves and decreased of their area, as well as reduced number of formed branches compared to those grown in environment with limited radiation. However, the content of methanol-soluble UV-B-absorbing compounds increased, and the concentration of chlorophyll $\mathrm{b}$ in leaves decreased in response to enhanced levels of UV-B (Day et al. 1996). It appears that seedlings are especially susceptible to damages induced by UV-B (Ballaré et al. 1995, Krizek et al. 1997, Deckmyn and Impens 1999). The increased content of compounds, which absorb this type of radiation, in the epidermal cells of foliage prevents UV-B penetration to the deeper layers of mesophyll cells. Thus, it protects them against damages. The lower concentration of chlorophyll $\mathrm{b}$ may be associated with adverse changes in photosystem II caused by intensive UV-B radiation (Greenberg et al. 1989). The final effect of enhanced radiation, in spite of increased content of bulk soluble UV-Babsorbing compounds, seems to be unfavorable to the juvenile stage of C. quitensis, which may be reflected in the impaired plant productivity in subsequent growing seasons (Ruhland and Day 2001). On the other hand there are some assumptions stating the positive effect of ultraviolet radiation on the generative propagation of D. antarctica and C. quitensis (Day et al. 1999). Furthermore, in other plant species were also reported some positive implications caused by enhanced UV-B levels, such as: a higher number of reproductive structures and their larger size (Barnes et al. 1990, Day and Demchik 1996). Therefore, it is difficult to determine the direction of the changes induced by this factor.

\section{CONCLUSIONS}

The complexity of the climate change causes tremendous difficulties in defining a clear and unquestioned way of modifications during the reproductive phase of the described plants. Under natural conditions, none of the factors do not occur alone. The factors described here co-occur at the same time so their effect can be quite different from those observed during simulations, which only imitate natural conditions. The changing climate components may impact not only on biota, but also to other abiotic factors. As a result, this may lead to increased or decreased intensity of other stress factors. Bokhorst's et al. (2007) observations indicate that, insignificant increase of temperatures, which may be favorable for plant growth and development, can reduce soil moisture, resulting in increased drought stress. Finally, it should be noted that in spite of observed global warming, polar regions 
are still haunted by the extreme weather events - such as drought or sudden temperature drops, which disturb the successful establishment of polar vascular plant in these regions.

\section{REFERENCES}

Ballaré C. L., Barnes P. W., Flint S. D., 1995, Inhibition of hypocotyls elongation by ultraviolet-B radiation in de-etiolating tomato seedlings, Physiologia Plantarum, 93(4), 584-592.

Barnes P. W., Flint S. D., Caldwell M. M., 1990, Morphological responses of crop and weed species of different growth forms to ultraviolet-B radiation, Am. J. Bot., 77, 1354-1360.

Bokhorst S., Huiskes Ad., Convey P., Rien A., 2007,The effect of environmental change on vascular plant and cryptogam communities from the Falkland Islands and the Maritime Antarctic, BMC Ecology, 7, 15.

Callaghan T. V., Emanuelsson U., 1985, Population structure and processes of tundra plants.and vegetation, [in:] White J. (ed.), Population structure of vegetation, Dr W. Junk Publishers, Dordecht, 399-439.

Convey P., 1996, Reproduction of Antarctic flowering plants, Antarctic Science, 8(2), 127 134.

Day T. A., Demchick S. M., 1996, Influence of enhanced UV-B radiation on biomass allocation and pigment concentrations in leaves and reproductive structures of greenhouse-grown Brasica rapa, Vegetatio, 127, 109-116.

Day T. A., Howells B. W., Ruhland C. T., 1996, Changes in growth and pigment concentrations with leaf age in pea under modulated UV-B firld treatments, Plant Cell Environ., 19, 101-108.

Day T. A., Ruhland C. T., Grobe C. W., Xiong F., 1999, Growth and reproduction of Antarctic vascular plants in response to warming and UV radiation reductions in the field, Oecologia, 119, 24-35.

Deckmyn G., Impens I., 1999, Seasonal response of six Poaceae to differential levels of solar UV-B radiation, Environmental and Experimental Botany, 41, 177-184.

Edwards J. A., 1974, Studies In Colobanthus quitensis (Kunth) Bartl. and Deschampsia antarctica Desv.: VI. Reproductive performance on Signy Island, British Antarctic Survey Bulletin, 39, 67-86.

Greenberg B. M., Gaba V., Canaani O., Malkin S., Mattoo A. K., Edelman M., 1989, Separate photosensitizers mediate degradation of the 32-kDa photosystem II reaction center protein in the visible and UV spectral regions, Proc. Natl. Acad. Sci., USA, 86, $6617-6620$.

King J. C., 1994, Recent climate variability in the vicinity of the Antarctic Peninsula, International Journal of Climatology, 14, 357-369.

Krizek D. T., Mirecki R. M., Britz S. J., 1997, Inhibitory effects of ambient levels of solar UV$A$ and UV-B radiation on growth of cucamber, Physiology Plantarum, 100, 886-893.

Pirożnikow E., 1996, Adaptive strategies of plants in the arctic desserts conditions, Dissertations Universitotis Warsoviensis, 441, Białystok. 
Ruhland T. C., Day A. T., 2001, Size and longevity of seed banks in Antarctica and the influence of ultraviolet-B radiation on survivorship, growth and pigment concentrations of C. quitensis seedlings, Environmental and Experimental Botany, 45, 143-154.

Smith L. I. R., 1994, Vascular plants as bioindicators of regional warming in Antarctica, Oecologia, 99, 322-328.

Smith R. C., Stammerjohn S. E., Baker K. S., 1996, Surface air temperature variations in the western Antarctic Peninsula region, [in:] Ross R. M., Hofman E. E., Quetin L. B. (eds), Foundations for ecological research west of the Antarctic Peninsula (Antactic Research Series vol 70), American Geophysical Union, Washington, 105-121.

Wookey P. A., Parsons A. N., Welker J. M., Potter J. A., Callaghan T. V., Lee J. A., Press M. C., 1993, Comparative responses of phenology and reproductive development to simulated environmental change in sub-arctic and high arctic plants, Oikos, 67, 490-502.

Wookey P. A., Robinson C. H., Parsons A. N., Welker J. M., Press M. C., Callaghan T. V., Lee J. A., 1995, Environmental constraints on the growth, photosynthesis and reproductive development of Dryas octopetala at a high Arctic polar semi-desert, Svalbard, Oecologia, 102, 478-489. 